\title{
Niemann-pick type b disease diagnosed in the
}

\section{adulthood}

\author{
Sinan Demircioğlu ${ }^{1^{*}}$, Celalettin Korkmaz ${ }^{2}$, Hilal Akay Çizmecioğlu ${ }^{3}$, Necdet Poyraz $^{4}$ \\ ${ }^{1} V$ an Yüzüncü Yul University, Faculty of Medicine, Department of Hematology, V an \\ ${ }^{2}$ Necmettin Erbakan University, Meram Medical Faculty, Department of Chest Diseases, Konya \\ 3 Academy Hospital, Internal Medicine Clinic, Konya \\ ${ }^{4}$ Necmettin Erbakan University, Meram Medical Faculty, Department of Radiology, Konya
}

\begin{abstract}
Niemann-Pick disease (NPD) type B is an autosomal recessive liposomal storage disorder. NPD type B can present later in life with predominantly visceral symptoms, and has a more favorable prognosis. The natural history of NPD-B is one of progressive hypersplenism and gradual deterioration of pulmonary function. In this paper, we presented NPD type B patient who were diagnosed at 41 years old while being followed for years with the diagnosis of interstitial lung disease.
\end{abstract}

Key Words: Niemann-Pick Disease, Type B, Lung, Splenomegaly

\section{Introduction}

Niemann-Pick disease is an autosomal recessive liposomal storage disorder characterized by the accumulation of sphingomyelin. The gene encoding the acid sphingomyelinase (ASM) enzyme, sphingomyelin phosphodiesterase-1 (SMPD1) gene, is mutated, leading to the accumulation of sphingomyelin in lysosomes of macrophages (1). The estimated prevalence of ASM (type A, type B) is approximately $1 / 250.000$ (2). Type $C$ disease results from the mutation of NPC1 and NPC2 genes that is associated with the impairment in cellular processing and transport of low density lipoprotein (LDL) cholesterol (3).

Type A disease is the most common form of the condition characterized by an acute neurological disorder. The highest incidence occurs in Ashkenazy Jews (2). Patients generally die within the first 2 to 3 years of life due to rapid progressive neurological dysfunction. NiemannPick disease type B, which presents itself at later stages of life, is a less severe form than type A disease, may occur in all ethnicities, and is associated with a better prognosis. It is also known as the chronic visceral form. NPD type B is characterized by the development of hepatosplenomegaly during infancy and childhood. Secondary thrombocytopenia resulting from hypersplenism may be seen. Severe hepatic involvement may occur due to swelling and fibrosis of hepatocytes resulting from the infiltration of foamy histiocytes (4). Other systemic manifestations include short stature as a result of delayed skeletal maturation, interstitial lung disease, hyperlipidemia, and ophthalmological abnormalities (5-7). Most patients do not have neurological impairment. The natural course of the disease includes progressive hypersplenism and a gradual decline in pulmonary functions $(8,9)$.

\section{Case Report}

This 41 year old patient reported dry cough and shortness of breath worsening with exercise for the past 8 years. He had been diagnosed with interstitial lung disease at the department of chest diseases, and was found to have bilateral groundglass appearance on chest $\mathrm{x}$-rays and areas of ground-glass intensities with patchy regions of cobblestone appearance, intra and inter-lobular septal thickening and preserved hypodense parenchymal areas in the upper lobes in highresolution computed tomography imaging (Figure 1). A biopsy of the lung parenchyma was performed which showed diffuse accumulation of foamy histiocytes in alveolar spaces. Splenomegaly and thrombocytopenia accompanied to these pathology findings may suggest a systemic metabolic disease in the patient. So the patient was referred to hematology. At the time he was 


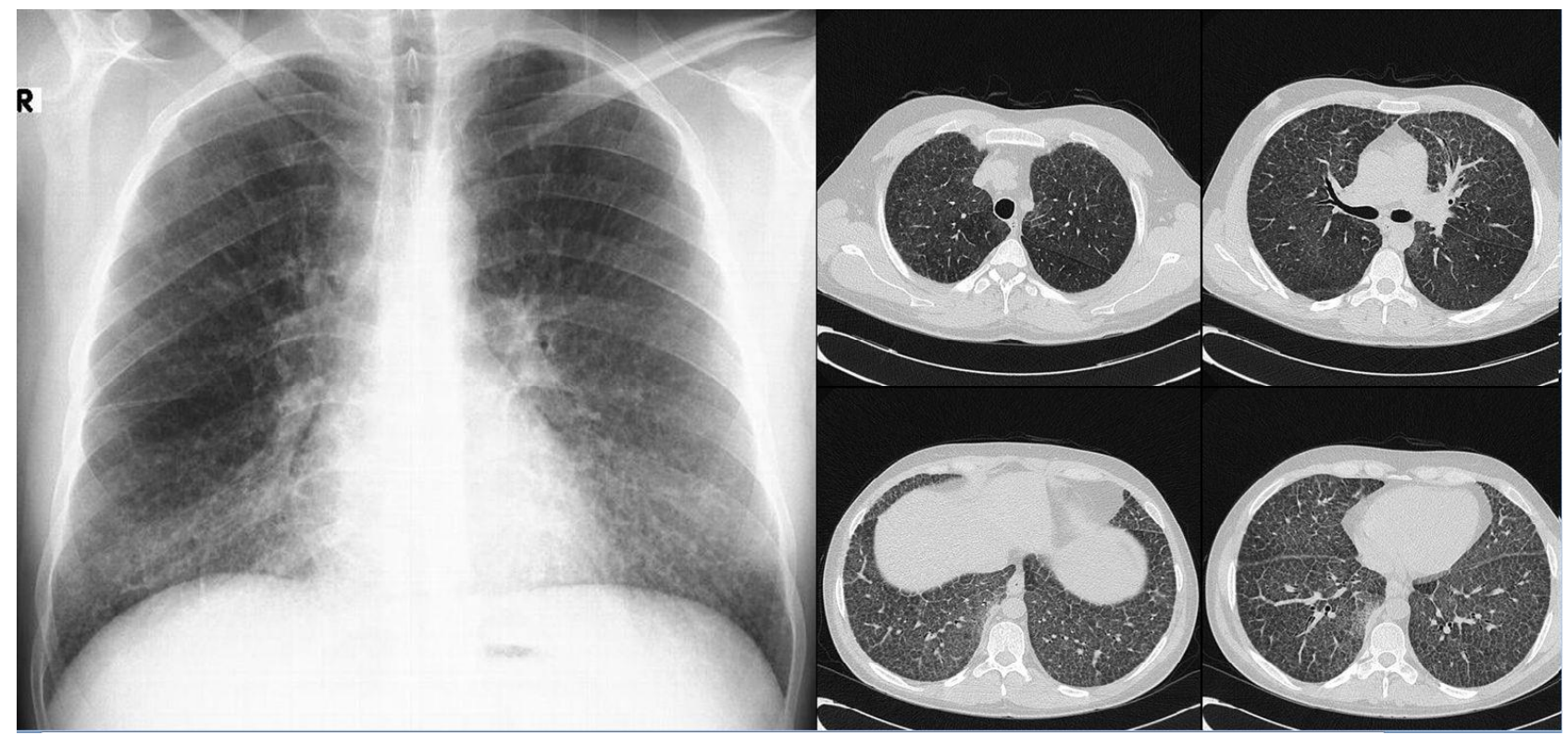

Fig. 1. Bilateral ground-glass appearance in lung graphy and high-resolution computerized tomography

referred to the hematology outpatient unit his blood parameters were as follows: white blood cell count 7400 / ul, hemoglobin $16.9 \mathrm{~g} / \mathrm{dl}$, platelets 113.000/ul. Abdominal ultrasound showed a liver size of $16 \mathrm{~cm}$ and spleen size of $19 \mathrm{~cm}$. Peripheral smears showed no atypical cells and suggested a normal platelet count. Also, single or conglomerating sea-blue histiocytes were found in the bone marrow biopsy (Figure 2). Acid sphingomyelinase activity was reduced at 0.5 $\mu / \mathrm{mol} / \mathrm{l} / \mathrm{h} \quad(>0.9)$. Due to reduced enzyme activity, a mutation analysis was performed that revealed a homozygous mutation of (c.1829_1831delGCC); (c.1829_1831delGCC) seen in Niemann-Pick disease. Triglycerides were 168 $\mathrm{mg} / \mathrm{dl}$, total cholesterol $175 \mathrm{mg} / \mathrm{dl}$, LDL 108 $\mathrm{mg} / \mathrm{dl}$, and HDL $33 \mathrm{mg} / \mathrm{dl}$. Ophthalmological examination was normal. The patient was diagnosed with NPD type B and placed under follow-up.

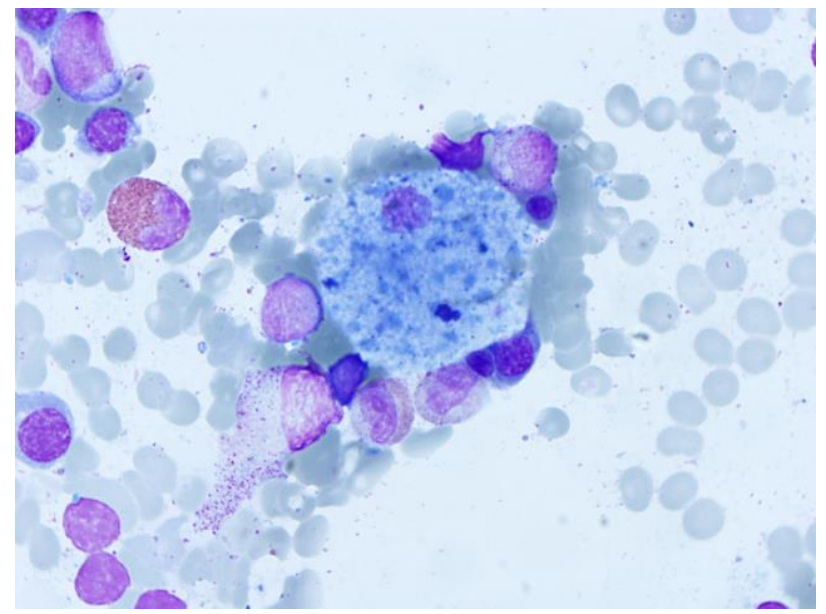

Fig. 2. Sea-blue histiocytes in bone marrow aspiration

\section{Discussion}

Clinical characteristics of Niemann-Pick disease type B include thrombocytopenia with hepatosplenomegaly, interstitial lung disease and lipid disorders (low HDL, high LDL, and triglyceridaemia). Diagnosis may also be established with low acid sphingomyelinase activity as well as identification of SMPD1 mutation. Our patient had a long history of pulmonary symptoms, splenomegaly resulting in thrombocytopenia, sea-blue histiocytes in the bone marrow, ASM deficiency and SPDM1 mutation.

Niemann-Pick disease type B is frequently associated with pulmonary involvement, characterized by progressive impairment of pulmonary functions in adulthood. Very rarely, it may be the presenting symptoms of the disease (10). In contrast, our patient had first sought medical assistance due to shortness of breath and dry cough.

Although pulmonary involvement may occur in all three types of NPD, it most frequently is seen in NPD type B (11). It may exhibit a wide variation of clinical signs and symptoms from asymptomatic cases to pulmonary failure. Initially the respiratory symptoms are generally mild with recurrent dry cough, moderately severe dyspnea with exercise, and pulmonary infections. However, rapidly progressive fatal pulmonary disease has also been reported (6). Nevertheless, the disease is generally associated with a slow progression of lung disease, similar to our case. 
Respiratory function tests generally reveal normal lung volumes together with reduced carbonmonoxide diffusion capacity (DLCO). Even in patients with significantly reduced DLCO, the lung volumes and flow rates may be well preserved (12). The pulmonary radiological findings in Niemann-Pick disease generally include reticular or reticulo-nodular pattern with or without septal lines mostly in the lower lung zones as well as the honeycomb appearance. Infiltrations initially start in the lower zones, progressing to all pulmonary areas with time (12). In these patients, pleural diseases and thoracic lymphadenopathy have not been define (13). Bronchoalveolar lavage or lung biopsy may confirm the lung involvement by the demonstration of wide and multivacoulated histiocytes (sea-blue histiocytes) containing fine and coarse granules with blue coloration using May-Grunewald Giemsa staining (11). In our patient sea-blue histiocytes were found both in lung and bone-marrow biopsies.

Niemann-Pick disease has no specific treatment, and supportive measures are generally used. Oxygen support may be administered in patients with interstitial pulmonary disease, while blood products may be used for patients with thrombocytopenia. Also correction of hyperlipidemia is recommended. Patients with splenomegaly should avoid contact physical activity. A diagnosis of NPD type B should be borne in mind in cases with unexplained splenomegaly, thrombocytopenia, and interstitial lung disease. In contrast with other storage diseases, diagnosis may be delayed until adulthood. The diagnosis may be easily overlooked due to rarity of this condition.

\section{References}

1. Schuchman EH, Wasserstein MP. Types A and B Niemann-Pick disease. Best Pract Res Clin Endocrinol Metab 2015; 29: 237-247.

2. Meikle PJ, Hopwood JJ, Clague AE, Carey WF. Prevalence of lysosomal storage disorders. JAMA 1999; 281: 249-254.
3. Morris JA, Zhang D, Coleman KG, Nagle J, Pentchev PG, Carstea ED. The genomic organization and polymorphism analysis of the human Niemann-Pick C1 gene. Biochem Biophys Res Commun 1999; 261: 493-498.

4. Takahashi T, Akiyama K, Tomihara M, et al. Heterogeneity of liver disorder in type $\mathrm{B}$ Niemann-Pick disease. Hum Pathol 1997; 28: 385-388.

5. Wasserstein MP, Larkin AE, Glass RB, Schuchman EH, Desnick RJ, McGovern MM. Growth restriction in children with type B Niemann-Pick disease. J Pediatr 2003; 142: 424428.

6. Guillemot N, Troadec C, de Villemeur TB, Clement A, Fauroux B. Lung disease in NiemannPick disease. Pediatr Pulmonol 2007; 42: $1207-$ 1214.

7. McGovern MM, Wasserstein MP, Aron A, Desnick RJ, Schuchman EH, Brodie SE. Ocular manifestations of Niemann-Pick disease type B. Ophthalmology 2004; 111: 1424-1427.

8. Wasserstein MP, Desnick RJ, Schuchman EH, et al. The natural history of type B Niemann-Pick disease: results from a 10-year longitudinal study. Pediatrics 2004; 114: e672-677.

9. von Ranke FM, Pereira Freitas HM, Mancano $\mathrm{AD}$, et al. Pulmonary Involvement in NiemannPick Disease: A State-of-the-Art Review. Lung 2016; 194: 511-518.

10. Nicholson AG, Florio R, Hansell DM, et al. Pulmonary involvement by Niemann-Pick disease. A report of six cases. Histopathology 2006; 48: 596-603.

11. Ahuja J, Kanne JP, Meyer CA, et al. Histiocytic disorders of the chest: imaging findings. Radiographics 2015; 35: 357-370.

12. Minai OA, Sullivan EJ, Stoller JK. Pulmonary involvement in Niemann-Pick disease: case report and literature review. Respir Med 2000; 94: 12411451.

13. Chung MJ, Lee KS, Franquet T, Muller NL, Han J, Kwon OJ. Metabolic lung disease: imaging and histopathologic findings. Eur J Radiol 2005; 54: 233-245. 